\title{
Providing Physical and Mental Health Support Using Medical Examination Data and Perceived Health
}

\author{
Makiko Fukuda, Eiji Marui, Fusako Kagitani \\ University of Human Arts and Sciences, Saitama, Japan \\ Email: mind910body116meer66@yahoo.co.jp
}

Received 26 February 2015; accepted 23 March 2015; published 25 March 2015

Copyright (C) 2015 by authors and Scientific Research Publishing Inc.

This work is licensed under the Creative Commons Attribution International License (CC BY). http://creativecommons.org/licenses/by/4.0/

\section{(c) (i) Open Access}

\begin{abstract}
Without ascertaining workers' perceived health, it is difficult to achieve behavioral modification even if health guidance is conducted. To investigate physical and mental health support emphasizing "positive health," we used the Total Health Index (THI) survey with the purpose of elucidating the association between medical examination data and perceived health. After obtaining medical examination data from 90 men, we analyzed their responses to the THI survey. The results suggested that age and abnormal medical examination data are associated with physical and mental complaints. In the analysis by age group, we found that men in their 20 s had more complaints of irregularity of daily life on the THI scale. The group who responded that they were not getting enough sleep had higher mean values of total cholesterol and fasting blood sugar. The group who responded that their meals were irregular had higher mean values of Body Mass Index, aspartate aminotransferase, and alanine aminotransferase. As confirmed by the THI, continuously supporting lifestyle improvement is important. The THI of the "health guidance" group indicated fewer physical health complaints and more aggression/extroversion than the "normal" group. In those for whom health guidance was applicable, participants who were "obese" and "hypertensive" had more aggression/extroversion and lesser extent of nervousness. Based on these findings, it was suggested that meaningful, personalized health support can be developed.
\end{abstract}

\section{Keywords}

Medical Examination Data, THI Survey, Physical and Mental Health Sciences

\section{Introduction}

Occupational health activities have focused on the concept of "negative health" [1] that is represented by a con- 
dition in which a worker is "not ill or weak" with the assumption that he/she is "healthy," emphasizing the physical health of workers. Furthermore, industrial health activities have developed health guidance for individuals with abnormal medical examination data with the purpose of achieving early detection, early treatment, and disease prevention through proven causes and evidence [2]. However, these activities face difficulties in enhancing the motivation of the "health guidance" group and in continuing guidance for continuous maintenance. Moreover, the industrial health activities were unable to confirm the physical and mental complaints enough to decide the health of the "normal" group. To assess the health support of workers with such facts in mind, it is necessary to focus on the concept of "positive health" [1] indicated by the "well-being" of individuals.

Support that considers multiple factors from mental, social, and cultural standpoints including psychology, awareness, subjectivity, values, or environment is also thought to be a challenge. Moreover, the process of providing health support to resolve problems or establish countermeasures for enhancing the health of each individual worker through the association between the objective medical examination data and subjective physical and mental complaints has also yet to be investigated.

The present study aimed to understand physical and mental health status and to ascertain perceived health using the Total Health Index (THI) survey [3], which was capable of quantitatively processing and evaluating (i.e., scaling and standardizing) complaints and subjective symptoms. The THI was developed in Japan to study a "healthy population," and the association between perceived health and objective health indices had also been reported [3]-[6]. However, no studies have examined the association of the THI with medical examination data. We therefore aimed to clarify such association in the present study.

\section{Method}

\subsection{Study Participants and Methods}

All the office workers, 108 persons, working at the Tokyo Metropolitan area branch of Company A Banking were investigated. Since female workers were only 18 persons, they were excluded from the analysis. The mean age \pm standard deviation of 90 men was $36.5 \pm 8.6$ years. The number of participants in each age group was: twenty-two 20 - 29-year-old (24.5\%), thirty-eight 30 - 39-year-old (42.2\%), twenty 40 - 49-year-old (22.2\%), and ten 50 - 59-year-old (11.1\%). The number of men and mean age \pm standard deviation for each job title were: 43 comprehensive workers (30.4 \pm 5.9 years old); 22 deputy managers ( $37.7 \pm 3.9$ years old); and 25 managers (46.0 \pm 5.9 years old).

After the medical examination, those who consented to participate in the study took the THI survey. The study was conducted between October 2013 and August 2014.

\subsection{Medical Examination Data}

Study participants were classified into those for whom health guidance was applicable ("health guidance" group) and those for whom it was not applicable ("normal" group) based on the medical examination data.

For blood tests, values determined to be within the normal range at the institutions for medical examination were applicable. Blood test variables were: complete blood count \{erythrocyte count (RBC), leukocyte count (WBC), hemoglobin level $(\mathrm{Hb})$, hematocrit $(\mathrm{Ht})$ \}, liver function \{aspartate aminotransferase (AST), alanine aminotransferase (ALT), $\gamma$-glutamyl transpeptidase $(\gamma$-GTP) , lipids \{total cholesterol (Total-C), high-density lipoprotein cholesterol (HDL-C), low-density lipoprotein cholesterol (LDL-C), triglycerides (TG)\}, glucose metabolism \{fasting blood sugar (FBS), HbA1c\}, and others \{uric acid (UA), total protein (TP), albumin (Alb), urea nitrogen (BUN)\}. Participants who had values outside the normal range were considered the "health guidance" group. Participants were classified into the "health guidance" group and "normal" group based on the presence/absence of each finding in resting electrocardiogram, chest (direct) X-ray imaging, hearing test, vision test, and urine test. Obesity index followed the classification by the Japan Society for the Study of Obesity 2000 with a Body Mass Index (BMI, $\mathrm{kg} / \mathrm{m}^{2}$ ) of $\geq 18.5$ and $<25$ as the normal range. The normal range for blood pressure was considered to be $<140 \mathrm{mmHg}$ for systolic blood pressure (SBP) and $<90 \mathrm{mmHg}$ for diastolic blood pressure (DBP), which are normal values according to the Guidelines for the Management of Hypertension 2009 by the Japanese Society of Hypertension.

\subsection{Total Health Index}

The THI survey was developed by Aoki, Suzuki, and Yanai in 1974 [3]. It is used to assess the effects of work- 
ing on an individual's health in industrial settings [7] [8]. This survey can also be administered over the internet at any time [9] [10]. Individuals are able to perform self-care through health advice based on the self-evaluation scores [10]. The THI recognizes perceived health as "a self-evaluation of one's own health status based upon whether it is good or bad, or sensing and perceiving one's own physical health subjectively and being notified of such results" [3]. There are 130 questions in the THI survey with three choices for responses: "Yes," "Neither," or "No." Scores are determined by allotting 3 points, 2 points, or 1 point, respectively, for each answer, with higher scale scores indicating stronger subjective symptoms [3]. The questions of the THI are classified into 12 scales. The number of questions and the content/meaning of each of the 12 scales, as well as their corresponding abbreviations, are shown in Table 1.

\subsection{Statistical Analysis}

For statistical analysis, the differences in the mean values between two groups and multiple comparisons after one-way analysis of variance (ANOVA) were analyzed using Excel10 and HALBAU7.

\subsection{Ethical Consideration}

This study was approved by the Ethics Review Board at the University of Human Arts and Sciences (Approval No. 364), and study permission from Company A Banking and consent from participants were obtained.

\section{Results}

\subsection{Medical Examination Data}

The mean age \pm standard deviation was $36.9 \pm 8.6$ years in the 70 men $(77.8 \%)$ of the "health guidance" group and $35.1 \pm 8.5$ years in the 20 men (22.2\%) of the "normal" group, indicating that the mean age was not significantly different.

Medical examination data by age group are shown in Table 2. TP and Alb were the highest in the 20 - 29year-old age group, and decreased with age. FBS was low in the 20 - 29-year-old age group, and increased with age. HDL-C was lower in 30 - 39-year-olds compared to 50 - 59-year-old.

\subsection{Total Health Index (Mean Score) by Age and Job Title}

Comparison of the THI by age group is shown in Table 3 . There were more complaints regarding LIFE in the

Table 1. Number of questions and the content/meaning of the 12 scales.

\begin{tabular}{|c|c|c|}
\hline Scale Name & $\begin{array}{l}\text { Abbreviation } \\
\text { (Number of Questions) }\end{array}$ & Content and Meaning \\
\hline Multiple physical complaints & SUSY (20) & Stiffness of neck and shoulders, body pain, feeling feverish, headache, etc. \\
\hline Respiratory complaints & RESP (10) & $\begin{array}{l}\text { Difficulty coughing up phlegm, runny nose, coughing, sneezing, throat pain, } \\
\text { etc. }\end{array}$ \\
\hline Complaints about eye and skin & EYSK (10) & Sensitive or itchy skin, rashes or hives, hyperemia of the eye, etc. \\
\hline Complaints about mouth and anus & MOUT (10) & Gum bleeding, halitosis, painful defecation, hemorrhoids, constipation, etc. \\
\hline Complaints about digestive organs & DIGE (9) & Pain or heaviness of the stomach, diarrhea, poor condition, indigestion, etc. \\
\hline Impulsiveness and irritability & IMPU (9) & Acting without thinking, impatience, excessive complaining, frustration, etc. \\
\hline Lie scale & LISC (10) & $\begin{array}{l}\text { Tendencies to make oneself look good, show off by disguising oneself, } \\
\text { vanity, etc. }\end{array}$ \\
\hline Mental instability & MENT (14) & $\begin{array}{l}\text { Worry about small things, face flushes, mentally tired, cold sweats, } \\
\text { restlessness, etc. }\end{array}$ \\
\hline Depressiveness & DEPR (10) & Sad, lonely, uninterested, melancholic and languid, not confident, etc. \\
\hline Aggression/extroversion & AGGR (7) & Psychologically extroverted, proactive, generous, not sensitive to cold, etc. \\
\hline Nervousness & NERV (8) & Nervous, anxious and excessive worrying, sensitive, fastidious, etc. \\
\hline Irregularity of daily life & LIFE (11) & $\begin{array}{l}\text { Staying up late and getting up late, irregular meals without breakfast, poor } \\
\text { appetite, etc. }\end{array}$ \\
\hline
\end{tabular}


Table 2. Medical examination data by age group $(n=90)$.

\begin{tabular}{|c|c|c|c|c|c|c|c|c|c|c|}
\hline \multicolumn{2}{|c|}{ Age (n) } & \multicolumn{2}{|c|}{$20-29$ y (22) } & \multicolumn{2}{|c|}{30 - 39 y (38) } & \multicolumn{2}{|c|}{$40-49$ y (20) } & \multicolumn{2}{|c|}{50 - 59 y (10) } & \multirow[b]{2}{*}{$\mathrm{p}$ value } \\
\hline & & Mean & SD & Mean & SD & Mean & SD & Mean & SD & \\
\hline BMI & $\left(\mathrm{kg} / \mathrm{m}^{2}\right)$ & 24.0 & 3.4 & 24.4 & 4.1 & 22.8 & 2.0 & 22.7 & 2.5 & 0.286 \\
\hline RBC & $\left(\times 10^{4} / \mu \mathrm{l}\right)$ & 499.6 & 28.6 & 503.6 & 30.8 & $476.1^{\mathrm{d}}$ & 21.9 & $473.2^{\mathrm{c}}$ & 26.5 & 0.001 \\
\hline $\mathrm{Hb}$ & (g/dl) & 15.37 & 0.83 & 15.32 & 0.70 & 15.14 & 0.87 & 14.92 & 0.84 & 0.416 \\
\hline \multicolumn{2}{|c|}{ Total-Pro (g/dl) } & 7.44 & 0.46 & 7.38 & 0.43 & $7.20^{\mathrm{c}}$ & 0.38 & $6.90^{\mathrm{a}}$ & 0.36 & 0.009 \\
\hline \multicolumn{2}{|c|}{ Albumin (g/dl) } & 4.86 & 0.31 & 4.73 & 0.23 & $4.50^{\text {bd }}$ & 0.25 & $4.40^{\text {bd }}$ & 0.14 & 0.000 \\
\hline \multicolumn{2}{|c|}{ Total-C (mg/dl) } & 198.0 & 29.7 & 189.3 & 27.5 & 201.3 & 24.1 & 197.0 & 18.9 & 0.387 \\
\hline \multicolumn{2}{|c|}{ HDL-C (mg/dl) } & 59.3 & 11.9 & 54.3 & 11.4 & 62.6 & 15.8 & $67.8^{\mathrm{c}}$ & 11.7 & 0.015 \\
\hline \multicolumn{2}{|c|}{ LDL-C (mg/dl) } & 120.6 & 25.0 & 117.5 & 26.6 & 122.0 & 18.4 & 114.0 & 23.0 & 0.816 \\
\hline \multicolumn{2}{|c|}{ TG (mg/dl) } & 103.7 & 81.4 & 101.5 & 43.8 & 101.6 & 40.4 & 107.6 & 60.1 & 0.991 \\
\hline \multicolumn{2}{|c|}{ FBS (mg/dl) } & 86.2 & 5.7 & 91.1 & 6.8 & $93.8^{\mathrm{a}}$ & 9.4 & $96.9^{\mathrm{b}}$ & 8.3 & 0.001 \\
\hline
\end{tabular}

Bonferroni correction p-value $\left(\leq 0.0083\right.$ at $5 \%$ level and $\leq 0.0017$ at $1 \%$ level); Pairwise comparisons, the $20-29$-y group ${ }^{a} p<0.05$, ${ }^{b} p<0.01$; Pairwise comparisons, the $30-39-y$ group, ${ }^{c} \mathrm{p}<0.05$, ${ }^{\mathrm{d}} \mathrm{p}<0.01$.

Table 3. THI of 12 scale scores by age group $(n=90)$.

\begin{tabular}{|c|c|c|c|c|c|c|c|c|c|}
\hline \multirow{2}{*}{$\begin{array}{l}\text { Age (n) } \\
\text { Scales }\end{array}$} & \multicolumn{2}{|c|}{$20-29 y(22)$} & \multicolumn{2}{|c|}{30 - 39 y (38) } & \multicolumn{2}{|c|}{40 - 49 y (20) } & \multicolumn{2}{|c|}{50 - 59 y (10) } & \multirow[b]{2}{*}{$\mathrm{p}$ value } \\
\hline & Mean & SD & Mean & SD & Mean & SD & Mean & SD & \\
\hline SUSY & 29.00 & 5.75 & 28.71 & 5.87 & 27.65 & 4.25 & 25.40 & 5.80 & 0.339 \\
\hline RESP & 14.50 & 2.37 & 14.42 & 4.01 & 13.95 & 2.87 & 12.50 & 2.73 & 0.404 \\
\hline EYSK & 15.09 & 2.97 & 14.58 & 2.96 & 14.15 & 2.63 & 13.10 & 3.89 & 0.378 \\
\hline MOUT & 12.77 & 1.73 & 12.26 & 1.73 & 12.35 & 2.10 & 13.00 & 3.41 & 0.683 \\
\hline DIGE & 13.09 & 2.37 & 12.74 & 2.85 & 11.95 & 1.47 & 12.80 & 3.54 & 0.558 \\
\hline IMPU & 16.96 & 3.14 & 17.47 & 3.33 & 17.10 & 3.52 & $14.10^{\mathrm{b}}$ & 2.55 & 0.047 \\
\hline LISC & 17.82 & 2.44 & 17.87 & 2.76 & 18.55 & 2.85 & 19.90 & 2.12 & 0.161 \\
\hline MENT & 23.23 & 4.19 & 23.92 & 4.86 & 21.70 & 4.21 & 20.60 & 6.00 & 0.158 \\
\hline DEPR & 13.73 & 3.17 & 13.68 & 2.90 & 13.75 & 3.60 & 12.50 & 2.91 & 0.735 \\
\hline AGGR & 16.80 & 1.80 & 15.34 & 2.27 & 15.70 & 1.98 & 15.60 & 2.50 & 0.543 \\
\hline NERV & 14.91 & 3.72 & 16.45 & 3.60 & 16.40 & 3.14 & 15.20 & 3.97 & 0.367 \\
\hline LIFE & 20.10 & 2.98 & 19.16 & 2.90 & $17.55^{\mathrm{a}}$ & 2.56 & $16.60^{\mathrm{a}}$ & 2.15 & 0.003 \\
\hline
\end{tabular}

Bonferroni correction p-value ( $\leq 0.0083$ at $5 \%$ level and $\leq 0.0017$ at $1 \%$ level); Pairwise comparisons, the $20-29$-y group ${ }^{\text {a }}$ $<0.05$; Pairwise comparisons, the 30 - 39-y group, ${ }^{\mathrm{b}}<0.05$.

20 - 29-year-old age group compared to other age groups.

Respondents who answered "yes" for not getting enough sleep (THI question 113: "Have you been sleeping less lately?”) had higher mean Total-C and FBS levels ( $<0.05)$ compared to those who answered "no.” Respondents who responded "yes" to having irregular meals (THI question 112: “Are your meals irregular?") had higher mean BMI, AST, and ALT values compared to those who responded "no" ( $\mathrm{p}<0.05$; data not shown).

Since we found no significant differences in the THI score between the 30 - 39- and 40 - 49-year-old age groups in the comparison of ninety 20 - 59-year-old men, we combined these age groups and assessed job titlerelated differences in a total of fifty-eight 30 - 49-year-old men. The results (Table 4) showed that the extent of NERV was the highest among those with the job title of deputy manager. 
Table 4. THI of 12 scale scores by job title $(n=58)$.

\begin{tabular}{cccccccc}
\hline Job Title (n) & Comprehensive Worker (19) & \multicolumn{2}{c}{ Deputy Manager (22) } & \multicolumn{2}{c}{ Manager (17) } \\
\hline 12 scales & Mean & SD & Mean & SD & Mean & SD & p value \\
\hline SUSY & 29.06 & 5.90 & 28.09 & 5.72 & 27.88 & 4.13 & 0.788 \\
RESP & 14.63 & 3.91 & 14.09 & 3.98 & 14.06 & 2.84 & 0.870 \\
EYSK & 14.74 & 2.10 & 14.96 & 3.57 & 13.41 & 2.22 & 0.219 \\
MOUT & 12.42 & 1.66 & 12.18 & 1.75 & 12.29 & 2.19 & 0.924 \\
DIGE & 12.58 & 2.89 & 12.86 & 2.70 & 11.82 & 1.34 & 0.435 \\
IMPU & 17.84 & 3.77 & 17.27 & 2.80 & 16.88 & 3.55 & 0.706 \\
LISC & 17.53 & 3.12 & 18.09 & 2.23 & 18.77 & 2.98 & 0.433 \\
MENT & 22.95 & 5.45 & 24.27 & 4.41 & 21.94 & 3.97 & 0.320 \\
DEPR & 13.05 & 2.91 & 14.27 & 2.73 & 13.71 & 2.48 & 0.482 \\
AGGR & 15.11 & 2.38 & 15.55 & 2.08 & 15.77 & 2.02 & 0.661 \\
NERV & 15.16 & 3.33 & $18.14^{\mathrm{a}}$ & 3.09 & 15.65 & 3.09 & 0.010 \\
LIFE & 19.58 & 3.07 & 18.46 & 2.64 & 17.71 & 2.65 & 0.150 \\
\hline
\end{tabular}

Analysis excluding the $20 \mathrm{~s}$ age group and 50s age group; Bonferroni correction p-value ( $\leq 0.0167$ at $5 \%$ level and $\leq 0.0033$ at $1 \%$ level); Between the job title of deputy manager and all job titles in total ${ }^{\mathrm{a}} \mathrm{p}<0.05$.

\subsection{Total Health Index Scale Scores by Medical Examination Variable}

For each variable of the medical examination, we divided the participants into a "health guidance" group and "normal" group at the mean value of each variable. The comparisons between these two groups are shown in Table 5. For obesity and hypertension, the "health guidance" group had more AGGR, and the "normal" group had a greater extent of NERV.

Study participants were divided into "low" and "high" groups at the mean scores on each of the 12 THI scales. The comparison of medical examination data between the two groups for each scale is shown in Table 6. The "high" group for SUSY had higher RBC, Hb, and Ht. For EYSK, the "high" group had higher BMI, Waist-C, WBC, Hb, Ht, Total-C, and LDL-C. Individuals with "high" AGGR had higher BMI, Waist-C, SBP, DBP, ALT, and $\gamma$-GTP $(\mathrm{p}<0.05$; data not shown).

\section{Discussion}

\subsection{Health Support from the Medical Examination Data}

The present study demonstrated decreased glucose tolerance and decreased protein synthesis in association with increasing age. The Industrial Safety and Health Act does not specify TP and Alb to be measured in routine medical examinations. Since the gender ratio at the present banking office was ill-balanced, the participants were only male banking workers, it would be the limitation of the study. The present study still suggested that individualized health support that ascertains the time-dependent changes of these variables is necessary.

\subsection{Health Support from the Total Health Index}

Previous studies on the 12 THI scales and age in men have shown high scores for SUSY, RESP, and EYSK in $\leq 29$-year-old men, EYSK in 30 - 39-year-old men, AGGR in 40 - 49-year-old men, and DEPR in $\geq 50$-year-old men [11] [12]. Our present study also demonstrated that 20 - 29-year-old men have higher scores for SUSY, RESP, and EYSK. Moreover, significant differences were observed in LIFE, suggesting that it is important to start providing health support to individuals in their $20 \mathrm{~s}$ to resolve lack of sleep and irregular meals. Men in the 50 - 59-year-old age group had higher scores on MOUT, indicating a necessity for oral care support to resolve halitosis and gingival bleeding. 
Table 5. THI of scale scores of the "health guidance” and "normal” groups ( $=90)$.

\begin{tabular}{cccccccc}
\hline \multirow{2}{*}{ Scales } & Variable & \multicolumn{2}{c}{ BMI \& Waist Circumference } & \multicolumn{2}{c}{ SBP/DBP } & \multicolumn{2}{c}{ Liver Function Markers } \\
\cline { 2 - 7 } & (n) & Normal (60) & Obese (30) & Normal (81) & Hypertensive (9) & Normal (68) & High (22) \\
\hline \multirow{2}{*}{ DIGE } & Mean & 12.87 & 12.23 & $12.80^{\mathrm{bc}}$ & 11.33 & 12.46 & 13.27 \\
& SD & 2.82 & 2.19 & 2.71 & 1.12 & 2.64 & 2.57 \\
\multirow{2}{*}{ AGGR } & Mean & 14.97 & $17.00^{\mathrm{b}}$ & 15.41 & $17.78^{\mathrm{bc}}$ & 15.27 & $16.82^{\mathrm{b}}$ \\
& SD & 2.05 & 1.68 & 2.12 & 0.97 & 2.09 & 1.97 \\
\multirow{2}{*}{ NERV } & Mean & $16.60^{\mathrm{a}}$ & 14.57 & $16.26^{\mathrm{b}}$ & 12.89 & 15.88 & 16.05 \\
& SD & 3.68 & 3.27 & 3.56 & 3.30 & 3.51 & 4.18 \\
\hline
\end{tabular}

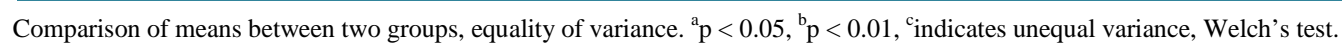

Table 6. Mean medical examination data according to each THI scale $(n=90)$.

\begin{tabular}{|c|c|c|c|c|c|c|c|c|c|c|}
\hline \multirow[b]{2}{*}{ Scales } & \multirow{2}{*}{$\begin{array}{c}\text { Mean Value } \\
\text { Comparison (n) }\end{array}$} & \multicolumn{2}{|c|}{ Obesity } & \multicolumn{4}{|c|}{ Complete Blood Count } & \multicolumn{3}{|c|}{ Serum Lipids } \\
\hline & & BMI & Waist-C & $\begin{array}{c}\text { RBC } \\
(\times 10000)\end{array}$ & WBC & $\mathrm{Hb}$ & $\mathrm{Ht}$ & Total-C & HDL-C & LDL-C \\
\hline \multirow{2}{*}{ SUSY } & Low (51) & 23.7 & 82.7 & 485.5 & 5656.4 & 15.02 & 44.60 & 193.6 & 60.8 & 115.6 \\
\hline & High (39) & 23.8 & 84.5 & $503.2^{\mathrm{b}}$ & 5746.2 & $15.54^{\mathrm{b}}$ & $46.38^{\mathrm{b}}$ & 196.7 & 56.3 & 123.2 \\
\hline \multirow{2}{*}{ EYSK } & Low (27) & 23.0 & 81.2 & 488.2 & 5377.8 & 15.07 & 44.71 & 189.8 & 61.0 & 114.3 \\
\hline & High (63) & $24.7^{\mathrm{c}}$ & $86.4^{\mathrm{d}}$ & 499.3 & $6085.3^{c}$ & $15.47^{\mathrm{a}}$ & $46.21^{\mathrm{b}}$ & $201.3^{\mathrm{a}}$ & 56.2 & $124.7^{\mathrm{a}}$ \\
\hline
\end{tabular}

Comparison of means between two groups, equality of variances ${ }^{a} t<0.05$, ${ }^{b} t<0.01$; Comparison of means between two groups, unequal variances Welch's test ${ }^{c} \mathrm{t}<0.05,{ }^{\mathrm{d}} \mathrm{t}<0.01$; Mean value comparison: low (n) $<$ mean $<$ high (n).

The present study showed more IMPU, MENT, and NERV in 30 - 39-year-old men and a greater extent of DEPR in 40 - 49-year-old men. Moreover, since the comparison of 30 - 49-year-old men by job title revealed that the extent of NERV was highest among those with the job title of deputy manager, it was suggested that ascertaining the mental complaints of 30 - 49-year-old men and providing them with health support are important.

A stress check has become mandatory, and this may lead to the understanding of stress; however, there is also a chance that this may be limited only to workers from the perspective of the protection of personal information. Cooperation with the surrounding people close to the workers, for example, family members, colleagues, superiors, or subordinates, is also an important part of health support.

\subsection{Health Support from the Medical Examination Data and Total Health Index}

Based on the objective medical examination data, the "health guidance" group had more AGGR. In addition, analysis by variable indicated that obesity and anemia were associated with more EYSK, and obesity, hypertension, and hepatic dysfunction were associated with more AGGR. Although further investigation is necessary with a higher number of participants, this study suggested that not only health guidance, but also health support for the improvement in perceived health can be developed from objective and subjective perspectives using the THI. In addition, normotensive individuals had more DIGE compared to hypertensive individuals, indicating that it is important to ascertain the physical complaints of the "normal" group for whom health guidance is not applicable.

In the comparison between "low" and "high" groups based on the mean of each of the 12 THI scales, complete blood count test results and AST and ALT tended to be high and HDL-C tended to be low in the "high" groups of mean scores of SUSP, EYSK, and AGGR. These results suggest that the THI, which can ascertain subjective perceived health, in addition to objective medical examination data, can be effectively utilized.

\subsection{Health Support for Positive Health}

Health promotion of workers has been defined as "a process that allows people to control and improve their own 
health as well as the deciding factors of such health” [13], and there has been an emphasis on the importance of support from the surrounding people such that one's own abilities can be extracted [14]. Kono stressed that "it is necessary in industrial nursing to provide meticulous support to each individual worker [15].” Moreover, we believe that influences from not only industrial nurses, but also people close to the workers are important, and consider this topic to be a future direction for investigation.

\section{Conclusion}

This study demonstrated an age-related association from medical examination data and the THI, and an association between abnormal medical examination data and physical and mental complaints in the male office workers. Based on these findings of an association between an objective health index of medical examination data and perceived health by the THI, it is meaningful to provide health support from both physical and mental aspects to encourage the "positive health" of workers.

\section{Acknowledgements}

We thank the President of Company A Banking for approving this study and the employees for their cooperation. We also thank Mr. Shosuke Suzuki, President of the International Eco Health Research Group for his thorough advice and guidance, and Professor Shigenobu Aoki at Gunma University for permitting the use of the THI survey over the internet.

\section{References}

[1] Downie, R.S., Fyfe, C.E. and Tannahill, A.J. (1990) Health Promotion-Models and Values. Oxford Medical Publications, Oxford University Press, Oxford.

[2] Green, J. (2000) The Role of Theory in Evidence-Based Health Promotion Practice? Health Education Research, 15, 125-129. http://dx.doi.org/10.1093/her/15.2.125

[3] Shosuke, S., Shigenobu, A. and Haruo, Y. (1989) THI Handbook. Shinohara Shuppan, Tokyo, 82-90.

[4] Tomoyuki, K., Shosuke, S., Kazuo, T. and Shigenobu, A. (1995) Factors Associated with Perceived Health. Journal of Health and Human Ecology, 61, 133-138. http://dx.doi.org/10.3861/jshhe.61.133

[5] Aviation Environment Research (2002) Perceived Health (THI). The Journal of Aviation Environment Research, 1-17. http://www.asahikawa-med.ac.jp

[6] Shosuke, S. (2002) A Self-Administered Symptom Check List, the Todai Health Index, and Application to Health Care of Small Scale Enterprises. Journal of Ergonomics in Occupational Safety and Health, 4, 5-11.

[7] Shosuke, S. (2005) Health Effects of Overworking-Measured in Health Check Questionnaire THI. The Journal of the Occupational Health Promotion Foundation, 10, 33-38.

[8] Shosuke, S. and Tsukioka, T. (2008) Working and Living Habits and Mental Health of the Features of the DoctorEvaluation by Questionnaire "Health Check Questionnaire THI". The Journal of the Japan Medical Association, 137, 744-751.

[9] Yanai, H. (2013) Multivariate Analysis Example Handbook. Asakura Shoten, 541-565.

[10] Total Health Index (2014) http://aoki2.si.gunma-u.ac.jp

[11] Takehiko, T., et al. (1989) Health Survey of Radiation Workers Such as Nuclear Establishments by THI. 122-130.

[12] Taiichi, S., Shigenobu, A., Shosuke, S. and Keiko, H. (1990) Changes of Subjective Complaints by Age-A CrossSectional Survey of Adult Female Population by the Todai Health Index Questionnaire. Journal of Health and Human Ecology, 56, 26-46. http://dx.doi.org/10.3861/jshhe.56.26

[13] Asano, H., et al. (2008) Predictive Validity of the Total Health Index for All-Cause Mortality Assessed in the Komo-Ise Cohort. Journal of Epidemiology, 18, 68-76. http://dx.doi.org/10.2188/jea.18.68

[14] Komulainen, P. (1991) Occupational Healthy Nursing Based on Self Care Theory. AAOHN Journal, 39, 333-335.

[15] Keiko, K. (2013) From Industrial Nursing Practice Foundation Can Be Seen in the Q\&A to Application. Medica Publication, 10-13. 